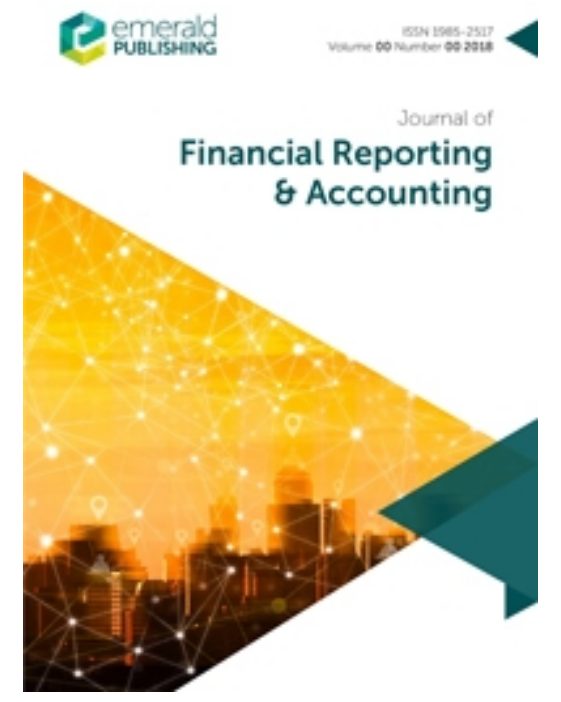

\title{
Higher Education Challenges: Accounting and Finance Academia in a Research-led Teaching Universities.
}

\begin{tabular}{|r|l|}
\hline Journal: & Journal of Financial Reporting and Accounting \\
\hline Manuscript ID & JFRA-01-2020-0007.R3 \\
\hline Manuscript Type: & Research Paper \\
\hline Keywords: & $\begin{array}{l}\text { Academic accounting staff, grounded theory, } \text {, London based University, } \\
\text { Academic accouresearch intensive University }\end{array}$ \\
\hline \multicolumn{2}{|l}{} \\
\hline
\end{tabular}

\section{SCHOLARONE ${ }^{\text {m }}$ \\ Manuscripts}




\section{Higher Education Challenges: Accounting and Finance Academia in a Research- led Teaching Universities.}

\section{Supporting Rationale of the Research}

The purpose of this research is to explore the challenges Business Schools face to find and sustain suitable accounting and finance (A\&F) staff. This could be done to explain the shortage of A\&F staff issue and to display this world-wide phenomenon. The paper contributes to the existing literature by showing the effect of supply and demand of the accounting and finance academia in a research led teaching University working in London. This case study shows this phenomenon in one of the most populated city of the UK. Many global business Schools are experiencing a severe shortage in accounting academics (Irvine et al., 2011, Smith \& Urquhart, 2018). In 2004, a committee from the American Accounting Association was appointed to assess the supply and demand for accounting PhD qualified faculty staff in the USA (CAAA, 2008). Another study in Australia shows that there is a shortage of PhD-qualified academics (Healy, 2007, cited on Irvine et al., 2008; James, 2008 ) and that 'Accounting Education at Cross Road' (Evans et al., 2010). In the United Kingdom, Duff and Monk (2006, p. 194) commented that 'University accounting and finance $(A \& F)$ departments are experiencing difficulty in attracting and retaining suitably qualified staff'. And one of the most recent study conducted by Smith \& Urquhart (2018) suggested that there are shortage in the supply of A \& F accounting academics in the labour market.

The shortage of A\&F academics has become a global issue (Duff and Monk, 2006; Beattie \& Goodacre, 2012; De Jager \& Frick, 2016; Smith \& Urquhart, 2018). There are a number of reasons that were discussed to explain such shortage. First, the low number of PhD students in A\&F (De Jager \& Frick, 2016). Second, the gap in salary between academia and industry professionals, which may hinder new entrants to academia. Third, the continuing increase of workload the accounting academics have to complete. Fourth, the high expectation of research output from the A\&F academics which may not be realised as a consequent to the heavy workload they have.

Accounting academics is a part in the Business Schools communities. They deliver and share their intellectual knowledge to the learning and teaching strategies in the Universities. With this issue of shortage, the Business Schools and Universities will 
suffer. This is the core issue that we would like to expose and to open the debate on how business schools can address this issue of shortage in A\&F staff and how business schools can deal with this issue.

The aim of this research is to explore and to open the debate on how business school can address the issue of shortage in A\&F staff. In particular, this research will find out challenges that face business Schools in finding suitable A\&F candidates to satisfy the research-led strategies, and how this would affect the research culture for the A\&F academia. Thus, the main research question of this study is 'What are the challenges facing the recruitment and retaining of A\&F staff in a research-led teaching university?'

The structure of this research reflects the deductive - inductive nature of the research methodology used in this study which is the grounded theory. The research starts with a brief review of the relevant literature on the accounting research led teaching environment and the shortage issue of A\&F academics. The purpose of this section is to inform the reader about the past studies and supporting evidence for the research problem. The second section describes the grounded theory as a research methodology used in this study for research design, data collection and analysis for this in-depth case study. The purpose of this section is to show to the reader the flow of the research and how this study has been undertaken. This is followed by the flow and development of the generated theory which is the challenges that face the business schools in finding and retaining A\&F staff. The purpose of this section is to achieve the research objective and to address the research question. Then the final section is to discuss research novelty, conclusion and recommendations.

\section{$2 \quad$ Literature Review}

Studies discussing the issues concerning A\&F staff can be grouped into two main themes. The first group consists of those studies that discussed the research-led teaching environment and how research is related to the teaching and accounting practices; while the second group consists of those studies that report the findings concerning the challenges facing the universities in recruiting A\&F staff.

\subsection{Research-led Teaching Environment}


The term 'research-led teaching' has attracted considerable attention in recent studies (Gibbs, 2002; Scott, 2002; Deakin, 2006). Research-based universities enhance the link between research and teaching. The in-depth case chosen is a research-led teaching university located in London. In accounting education, Kaplan (1989) has emphasized the interrelationship between research-teaching-practice, where these three functions should be performed by the A\&F academics and there should be a balance between the functions whereby each function complements and enhances another. No function has a 'monopoly' (Kaplan, 1989, p.129) over another.

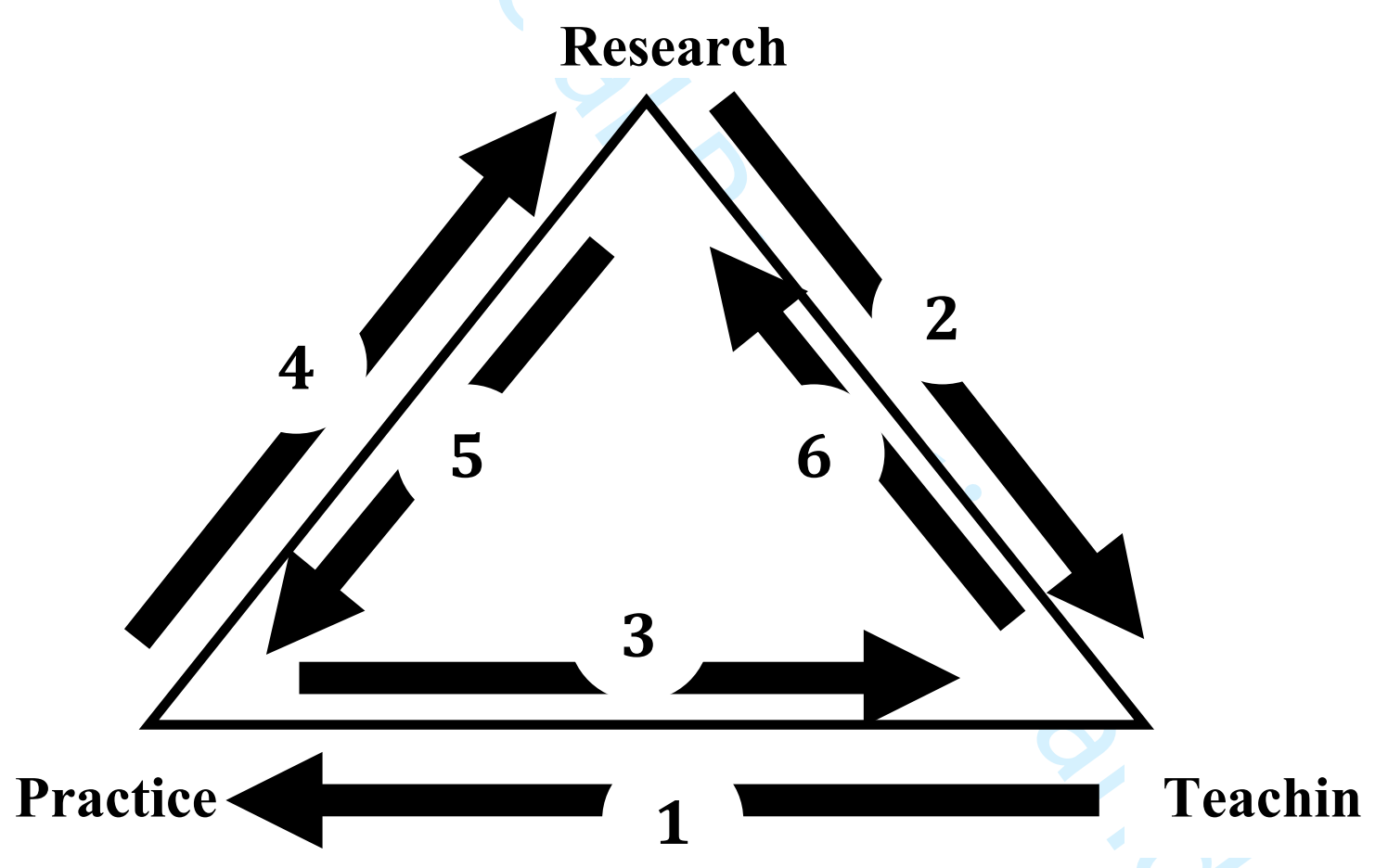

Six arcs of the research-teaching-practice triangle (Kaplan, 1989, p. 129)

One can see from arrow (1), which links accounting teaching to the practice, this fulfils the market requirement in our teaching strategy. In this way, the accounting academia will transfer their practical experiences to the new generations of accounting graduates. Arrow (2) links the accounting research to the accounting teaching, where the research affects our teaching; this passes the stock of knowledge to the new generation of accounting students. Arrow (3) connects practice to teaching, where the latter reflects 
traditional practice. In the accounting field, it is essential to teach and deliver some traditional practice to our students. Arrow (4) connects research to practice; accounting research should be affected by the current practices. According to Kaplan (1989), publication is a form where research can be linked to current practices. Arrow (5) connects practice to research; this arrow represents the research actions that have been affected by the technology and innovation from which society would benefit. Parker et al. (2011) has compared how accounting researches should be linked to accounting practices, and how the impact of research in a discipline like medicine, and the development of new drugs affect their practices, which in turn benefit society.

Arrow (6) is the most 'curious' (Kaplan, 1989, p. 131) arrow in this triangulation: how teaching affects accounting research. It is essential to link our teaching to our research, Duff and Monk (2006, p. 9) make three assumptions in the reasoning for an academic to link teaching and research. The first supposition is that the academic is researching an area that is of relevance to the curriculum being taught, hence moving the subject forward. Second, it is believed that by researching the same area, the quality of the academic's teaching will be enhanced. The third assumption is that teaching quality will enhance student learning.

When a business school is in a research intensive environment, research is linked to teaching. Teaching accounting modules are allocated to the accounting members of staff based on the staff research expertise. Teaching is linked to research, where the accounting modules are enhanced by the accounting staff research expertise. Research is linked to practice in research led Universities, the professional development of the accounting staff links research to practice. Practice in turn affects research, accounting staff's researches in business Schools are affected by the accounting professional life. To link Kaplan (1989) to the research aim and objective, one can see that a discipline as accounting should be thought to be an ideal example of how an A \& F academia can teach accounting.

\subsection{A\&F Academia}

There is a recent research trend to assess the shortage of accounting staff in a number of countries. In the United States of America, the American Accounting Association has a project 'Accounting Academy at a Tipping Point' (CAAA, 2008). In this AAA project, this tipping point for accounting academy is between the renewal and decline. The signs of potential decline are: accounting doctoral supply, business school policies, accounting 
research issues and the current faculty demographics. In the USA, the supply of doctorates are inadequate compared to the demand in the field of academia; according to the project figures, the supply is almost half of the future demand of accounting academia. The policies in the American universities' business schools dominant their support to the MBA program with relatively low salaries compared to accountants' salaries in industry. According to the American project, there are accounting research issues such as the publication review and how this review is difficult. While in the current faculty demographics there is erosion in the number of accounting staff and a majority of them are near retirement.

The Institute of Chartered Accountants in Australia issued a report in 2010 entitled 'Accounting Education at Cross Road' (Evans et al., 2010). In this report, Wright and Chalmers (2010, p. 76) explored accounting academia in Australia:

There is concern about the shortage of accounting academics because the discipline fails to attract high quality graduates and the existing workforce is ageing.

In Australia, there is concern regarding finding suitable accounting academics. Wright and Chalmers $(2010$, p. 76) further comment that the problems with the shortage of suitable accounting academia are due to research:

Research causes concern, particularly to junior staff. There are expectations regarding research outputs and grants. For staff without a PhD or a track record of research, there is a requirement that they will complete that PhD in addition to their other duties.

The problem with appointing early career researchers is that they are 'research intensive'. Wright and Chalmers (2010) argue that completing a $\mathrm{PhD}$ is a requirement for those new career researchers to have the ability to retain their careers in the Australian universities. In a study done by Guthrie et.al (2014) on the Australia's academic context, the study investigated the challenges faced by them, the findings showed there is a need for Australian staff to remain in their professional and expertise area (Guthrie et.al, 2014, cited in Samkin \& Schneider, 2014)

In the United Kingdom, in a study by the Universities and Colleges Employers Associations - UCEA (2002), it has been shown that the appointment of A\&F staff is one of the most problematic issues that the universities face. There have been research debates for almost two decades about accounting academia in the UK higher institutions (Holland, 1991; Wilson, 1988; Weetman, 1993; Brown et.al, 2007). 
Duff and Monk (2006) have discussed the issues the UK universities face in recruiting new appointees in $\mathrm{A} \& \mathrm{~F}$, positing that there are a number of reasons for this phenomenon:

- The wide salary gap between academia and industry professionals. 'Salaries for a partner in assurance services in London are reported as starting at £75,000, even in a small firm. In contrast, the salary for a lecturer range from $£ 26,884$ to $£ 39,269$ (inclusive of London weighting)’ Duff and Monk (2006, p. 194).

- The difficulty in achieving publications in highly rated journals.

- Too great a workload in teaching and marking due to the limited number of A\&F staff.

It is now clear that there is a universal issue in finding A\&F staff, not only for reasons such as the research intensiveness of the UK universities and a teaching overload, but most obviously due to the salary gap between the industry and the academia. As was observed in 2006, the salary in the industry field can reach up to three times the salary scale in the academia.

From this point, we need to explore the issues facing business schools research led in finding and retaining accounting staff.

\section{$3 \quad$ Research methodology}

The empirical analysis and theory generation used in this study is based on a grounded theory (GT) approach. GT aims to develop an inductively derived theory out of research data by achieving a close relation between the theory generated and the data collected. Whereas interactionists regard (observation of) human interaction as their basic source of data' (Denzin, 1989, p. 5), grounded theory generation includes additional data sources such as interviews, written reports, and documents that relate to the research phenomenon. Grounded theory was introduced by Glaser and Strauss in 1967 as a methodology that aims to discover a theory from data. Thereafter, Glaser and Strauss (Reetley, 2004) diverge in the principles and procedures they follow to generate a grounded theory. The Glaserian approach (Glaser, 1992) refers to the principles and procedures to be followed so that a GT 'emerges' during the course of the action of research. Glaser believed that the GT researcher should begin with 'wonderment', that is, to keep an open mind to the true issues in the field of research. The Straussian approach (Strauss and Corbin, 1990, 1998 and 2007) on the other hand, refers to the principles and 
procedures to be followed in order to 'build up' a theory. Strauss and Corbin believed that the GT researcher should do more than just wait for the theory to emerge; they noted that the GT researcher should begin with a general idea and then he/she needs to develop a more structured approach to the observed coding and data analyses to 'build up' a generated theory.

Therefore, we believe the Straussian grounded theory approach to be the most suitable approach to create and innovate new ways in which to deal with the challenges that face business schools research led in finding and retaining A\&F staff. The following section explains our research design based on the Straussian grounded theory approach.

\subsection{Research Design}

The first step in research design is to review the literature (Strauss and Corbin, 1990). From the literature review process, the main pre-determined themes are identified, which constitute the basis for the initial questions in the interview guide. The second step of research design is to select the unit of data (Pandit, 1996). The unit of data (or the raw data on which the research is built upon) should be selected according to the principle of theoretical sampling:

The process of data collection for generating theory whereby the analyst jointly collects, codes, and analyses his data and decides what data to collect next and where to find them, in order to develop his theory as it emerges. (Glaser and Strauss, 1967, p. 45)

In this research, there are two types of data collection, the first is archival data collected from Human Resources department in the University under study, and the second is via interviews. As this research is ongoing we report on one case study in this paper. The interviews were in-depth semi-structured interviews. Three interviews (Table 1) were completed with the head of the Accounting and Auditing Research Group in the business school under study (interviewee 1); a senior lecturer in the Accounting and Auditing Research Group in the Business School who has been working in the Business School for a long time and participated in many job interviews for A\&F staff recruitments (interviewee 2); and a senior management member in the 
Business School to solicit their views about the A\&F staff (interviewee 3). Those interviewees were selected as they are involved in the recruitment process of the accounting and finance staff in the case study. This study was conducted over a period of 6 months (September, 2011 until June, 2012)

\begin{tabular}{|l|l|l|}
\hline Interviewee 1 & $\begin{array}{l}\text { Head of the Accounting and } \\
\text { Auditing Research Group }\end{array}$ & $\begin{array}{l}\text { Teaching and working in the } \\
\text { field of accounting education } \\
\text { for more than 30 years }\end{array}$ \\
\hline Interviewee 2 & $\begin{array}{l}\text { Senior Lecturer in the } \\
\text { Accounting and Auditing }\end{array}$ & $\begin{array}{l}\text { Teaching and working in the } \\
\text { field of accounting education } \\
\text { for more than 30 years }\end{array}$ \\
\hline Interview 3 & Senior Lecturer in Management & $\begin{array}{l}\text { Teaching and senior } \\
\text { management of the school } \\
\text { and has experiences more } \\
\text { than 25 years in recruiting } \\
\text { staff in business schools. }\end{array}$ \\
\hline
\end{tabular}

\subsection{Selection of Interviewees}

In this research we focused on the A\&F academia in a business school in a London based research led University in order to gain an insight into the assessment of the shortage of suitable candidates in the UK. There were two main reasons for choosing this business school to be the case study: the high turnover for the accounting staff during the last 5 years and the demographical location of the University - located in London, where cost of living is higher than other places in the UK. Three semi-structured in-depth interviews were conducted in December, 2012. Every effort was made to get the interviewees to explore new ideas and enrich the research via their personal experiences, without pressure. The interviews were audio-taped and then transcribed. These transcripts (approximately 10,700 words) were used as the basis for data analysis. Notes were also taken during the interviews. In addition, general reflection notes (regarding interview contexts, apparent relationships between different interviews and contexts, impressions of each interviewee's reactions to the interview questions, etc.) were noted immediately after the interviews. The primary criterion for determining the number of interviews was 
data saturation or redundancy (Lincoln and Guba, 1985), that is, when an additional interview did not yield any significant new insights. These semi-structured interviews are characterized by being an intermediate form between a structured questionnaire and unstructured questionnaire (King, 1994); a structured open-responses interview was specifically chosen to reflect the exploratory power of the research and to reach theory saturation. While we argue that the saturation has been achieved for this particular case but this case should be seen as a part of a series of cases that are being undertaken to achieve the theory saturation for the complete study.

\subsection{Data Analysis}

Each interview was analysed manually to understand what the interviewees meant, the meanings being the selected raw data for the coding of the dataset. The Straussian approach suggests the analysis should be done line by line to discover the codes and then to show how they can be linked to each other to form the generated theory.

There was therefore bound to be a high level of researchers' involvement in this analysis. Strauss (1987), and Lincoln and Gupta (1985) suggest that coding is complete when the analysis itself appears to have run its course, that is, when all the incidents have been coded and where categories are 'saturated' as to the content of their coded meanings.

\section{$4 \quad$ Findings and Data Analysis}

The data analysis is a two-stage process; the first is an analysis of the number of job advert and job offered for A \& F staff and the second through interview analysis. The first analysis is the count of job adverts and job offered in order to discover if there is a problem in recruiting suitable A\&F staff in the Business School.

\subsection{Human Resources data}

In order to show whether or not the business school under study faces a problem in finding suitable A\&F staff, we refer to the job adverts for A\&F posts over a period of five years from January 2007 to December 2011. 
Table 2 shows the accounting job post, count of application forms, short listing count and the number of job offered from the business school under study.

\begin{tabular}{|c|c|c|c|c|}
\hline years & Job Post title & Application count & $\begin{array}{c}\text { Short listing } \\
\text { count }\end{array}$ & Job offers \\
\hline \multirow[t]{3}{*}{2007} & Lecturer & 11 & 4 & 1 \\
\hline & $\begin{array}{c}\text { Senior } \\
\text { lecturer/ } \\
\text { Lecturer }\end{array}$ & 9 & 0 & 0 \\
\hline & $\begin{array}{c}\text { Senior } \\
\text { lecturer/ } \\
\text { Lecturer }\end{array}$ & 22 & 3 & 1 \\
\hline 2008 & $\begin{array}{l}\text { Senior } \\
\text { lecturer/ } \\
\text { Lecturer }\end{array}$ & 20 & 0 & 0 \\
\hline \multirow[t]{6}{*}{2009} & Lecturer & 18 & 1 & 1 \\
\hline & Senior lecturer & 5 & 1 & 1 \\
\hline & Senior lecturer & 2 & 1 & 0 \\
\hline & Professor & 5 & 1 & 1 \\
\hline & Reader & 9 & 1 & 0 \\
\hline & Reader & 6 & 2 & 1 \\
\hline \multirow[t]{10}{*}{2010} & Reader & 17 & 0 & 0 \\
\hline & Lecturer & 11 & 0 & 0 \\
\hline & Senior lecturer & 6 & 1 & 1 \\
\hline & Lecturer & 10 & 0 & 0 \\
\hline & Senior lecturer & 4 & 8 & 0 \\
\hline & Lecturer & 11 & 2 & 0 \\
\hline & Senior lecturer & 1 & C & 0 \\
\hline & Lecturer & 9 & 3 & 0 \\
\hline & Senior lecturer & 4 & 0 & 0 \\
\hline & Senior lecturer & 1 & 1 & 1 \\
\hline 2011 & Lecturer & 16 & 0 & 0 \\
\hline Total & & 197 & 18 & 8 \\
\hline
\end{tabular}

As one can see from Table 2, the business school under study has placed advertisements for accounting post for 21 counts at all levels from lectureship to professorship in efforts to find suitable A\&F staff to satisfy the accounting teaching and research requirements of the Business School. Of these 21 counts, 13 adverts result in 0 job offers which clearly show how the business school under study recruitment criteria are hurdle to new appointees without good research profile. Consequently, it has been difficult to find suitable A\&F staff in this research intensive led University. And of these 21 advert counts, 18 candidates were shortlisted and invited for interviews, and only eight 
candidates were offered a post. It is clear that there is a problem in finding suitable A\&F candidates in the university under study.

\subsection{Interviews Findings and Analysis}

The generated theory for the higher education challenges in respect of A\&F academia staff in research-led teaching universities is based on the use of grounded theory as a research methodology. The questions in the interview guide were used to achieve the research objective as a part of the overall research objective. The following codes arose from these interviews conducted. During the coding analysis, some interview transcripts quotations are repetitive, as one or more codes can arise from the same interview transcript quotation.

\subsubsection{Recruitment Criteria}

The interviewees concluded that the recruitment criteria may make the process of finding suitable candidates in accounting academia to work in this business school under study difficult, in particular the requirement of a good research profile. Interviewee 1 commented

Well I think that we don't have much problem in attracting people to teach accounting, but we do have a problem with finding people who have got the track record of research that would like them to have in order to make them suitable.

The ability to attract applicants is demonstrated in the number of applications received, but the issue of finding 'suitable' candidates matching the recruitment criteria set by this business school under study is demonstrated in the eventual number of appointments. Having a good track record of research is a hurdle for many applicants. Interviewee 1 continues to discuss this issue:

So, here it says 'suitably qualified staff' - this is the wording of Duff and Monk. In I think that what is 'suitable' to us is in quite a high demand because we are a business school that is trying to move up the rankings; we're trying to improve ourselves all the time, I think we are making quite high 
demands on what we think is 'suitable' in an applicant. In other universities, like my previous university, somebody who was considered to be 'suitable' might not have a strong publication record, a strong record in attracting funds, a strong potential impact case for example, and all the things that are very important to the REF.

The business school under study has jumped up in the league table over the past few years. Hence, putting these criteria enables this business school under study to follow its research strategies successfully. When it comes to the A\&F staff, these criteria could be relaxed, as suggested by Interviewee 2:

We have had to relax our criteria, the universities' criteria is draconian, expecting people to be qualified accountants, have post graduate degrees, $P h D$ 's and publications. In accountancy there is a view, in the profession, that if you have a PhD you are over qualified.

Diagram 1

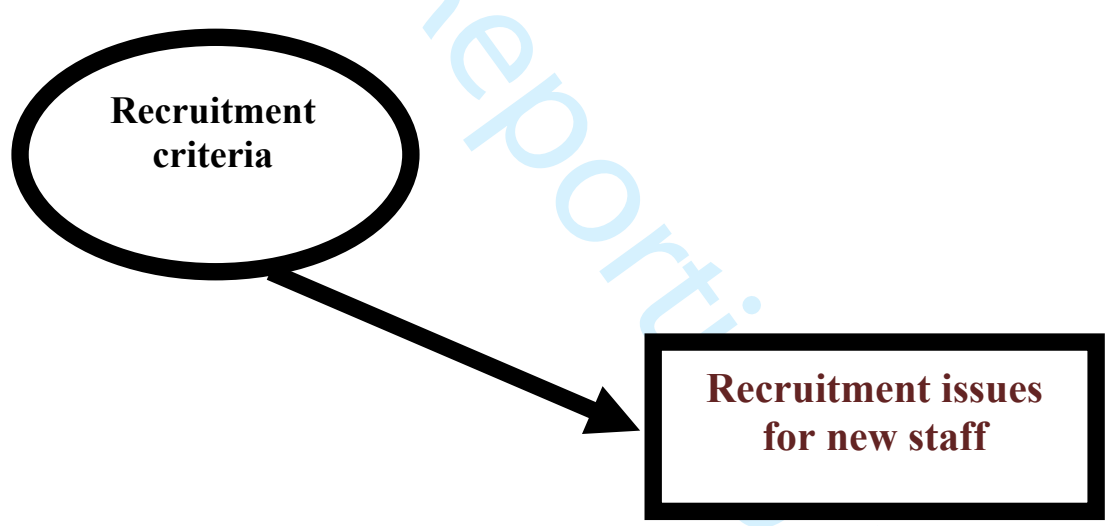

\subsubsection{PhD Holders vs. Qualified Accountants}

Another problem with the recruitment of new accounting staff in this business school under study is the issue of 'PhD holders vs. qualified accountants'. An accounting member of staff can be a $\mathrm{PhD}$ holder or a professionally qualified accountant, the accounting education is a requirement for both. Interviewee 2 commented:

We have had to relax our criteria, the universities' criteria is draconian, expecting people to be qualified accountants, have post graduate degrees, PhD's and publications. In accountancy there is a view, in the profession, that if you have a PhD you are over qualified. And therefore many people 
will not do a PhD unless they really have set their career sites on a university academic post. We have to relax our criteria slightly otherwise we wouldn't have suitable candidates. "

In industry, professionally qualified accountants gain their experience from practical issues in the field. Interviewee 2 continued:

[with] a professional qualification with experience you are better placed than a PhD because one of the problems with PhDs is that they are too specialised. A professional education, gives you a wider sphere.

For teaching purposes at undergraduate level, both $\mathrm{PhD}$ holders with good research profiles or qualified accountants with a professional background can deliver the knowledge skills required. But at a higher educational level (Master level or PhD level), $\mathrm{PhD}$ holders with a research intensive profile are required, as was suggested by Interviewee 1:

[professional accountants] may bring experience of working in business so the teaching may not have been their first choice of career. The other thing that they may bring is experience of working as a professional accountant in practice so that's another thing that feeds into their teaching. So I'm just trying to say that there are dimensions to the teaching fellow approach which are extremely valuable. Now let's look at what you were talking about which was the research active academic who's teaching

Interviewee 1 continued:

at other institutions they may have a number of MSC programmes with different names where each one of them will need some accounting modules or maybe $A \& F$ modules. Therefore that creates the need to have more academic staff who can teach those things. So, as you quite rightly pointed out, next year if the programme is validated, we'll be launching the first MSC in accounting and business management so we will have a need for extra staff"

\section{Diagram 2}

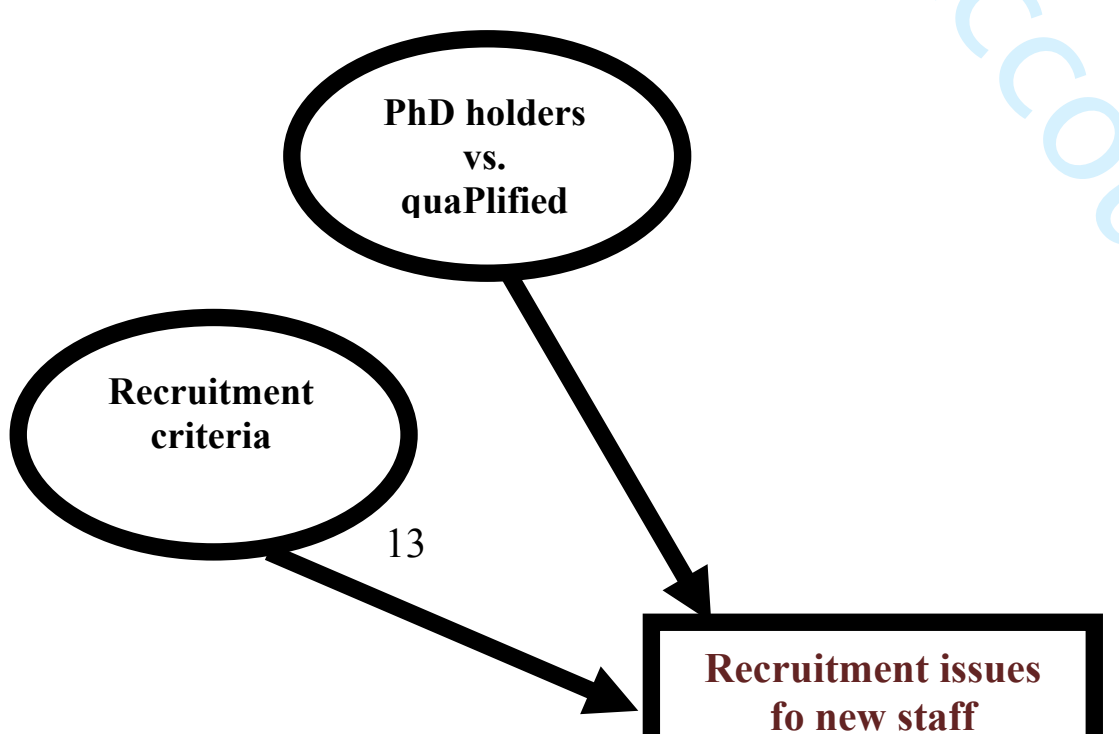




\title{
4.2.3 Demographic Effect
}

Being in London and near the airports are advantages for international students and for those travelling on a frequent basis. Living in London may not be attractive for some accounting academia, as the cost of living is high and may absorb most of their salary. When the interviewees were asked about the reasons for the staff turnover, Interviewee 2 responded:

\begin{abstract}
Because they don't feel valued and they are certainly underpaid. So it is very easy in London to move, particularly if you are a younger member of staff, as opposed to somebody of my age, it is very easy to move because there are many universities to go to, you don't have to move house, you have many options.
\end{abstract}

Being in London makes it easy to move from one university to another, especially if the member of staff is a junior researcher and has a good research track record. This would not be the case with clusters in the countryside, as it would be difficult to move from one university to the other without moving home and family. This view is supported by Interviewee 3, who said:

London has a particular affect. There is a higher turnover of staff in all London universities, compared to, I will just take as my example because I know it, okay I'll take two places, Bristol and University of East Anglia. People hardly ever leave from those universities, why, because they are in the countryside or in places where people are longing, really want to work.

Diagram 3 
A location in London can affect the recruitment of new accounting staff and can also play a role in rapid accounting staff turnover as the move to other universities in London can be easy.

\subsubsection{Competition with Other Universities}

As previously stated, being one of the London-based universities makes it easy to move from to a competitor university in London. The supply and demand of A\&F staff plays a role in attracting people in the UK. With the increasing demand for well qualified A\&F staff, it is easy to move from one London University to another. Interview 1 commented:

I think the factors that are involved are probably things to do with the market; the market is an important factor. If what Duff and Monk say is that there are problems across the sector in attracting accounting and finance staff, then that suggests there is more demand in the market for these kind of people than there are people to supply the demand. So people will be able to move on quickly and get better situations. Perhaps they can earn more, get promotions or simply work nearer to the place where they lived or would most like to live.

Interviewee 2 said that:

it is very easy in London to move, particularly if you are a younger member of staff, as opposed to somebody of my age, it is very easy to move because there are many universities to go to, you don't have to move house, you have many options.

\section{Diagram 4}

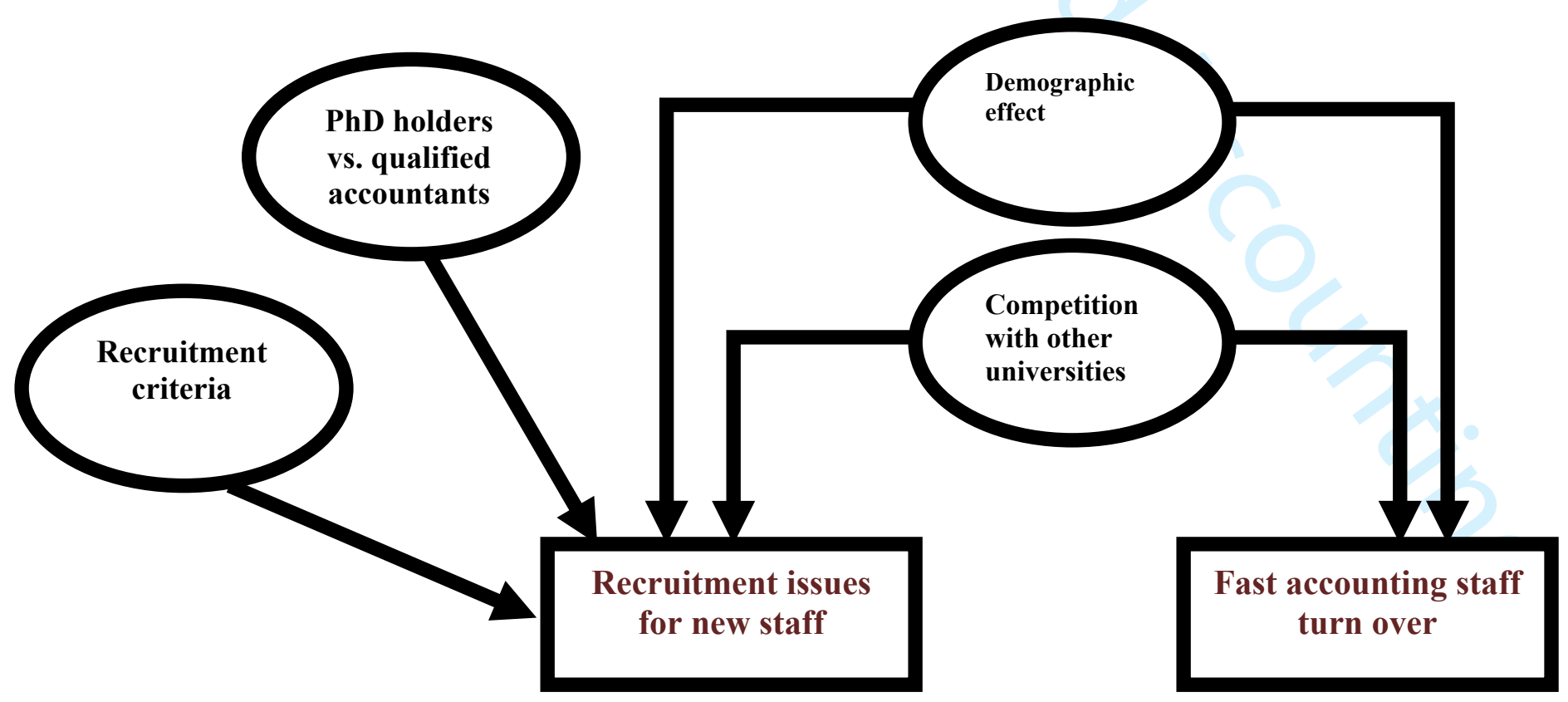




\subsubsection{Research Intensive}

As stated earlier, research plays a vital role in this business school under study. This research intensive criterion plays a role in the recruitment of new staff and in accounting turnover over a short period of time. Based on the data collected from the interviewees, it can be observed that the selection process is dependent on a good research profile. For the existing accounting staff and with their teaching commitment, again this University's research intensive ethos plays a role for some to move from to other universities. Interviewee 1 said:

we have very high entry criteria, which seem to be slowly, slowly getting a bit more demanding. Then going back to what is the fundamental essence of your question, we definitely have a problem in attracting those of this very high calibre and we have a problem in retaining the good people. One reason might be that they come along with a good profile, but they don't live up to the past! As we often say to our accounting students [in the context of historical nature of financial reporting]: 'The past is not necessarily a guide to the future'.

This business school under study is 'research intensive'; for new staff, it is a hurdle to be appointed without a good research track record. Interviewee 3 also said

Well, rather than a school, , as an institution, as a university, says that it is research intensive, like many, well in fact most really of our sort of universities that are in the same, I don't want to say level but ranked more or less as we are ranked. You know old universities, old universities say we are research led, we are research intensive, whatever word you want to use and that applies across everything. 


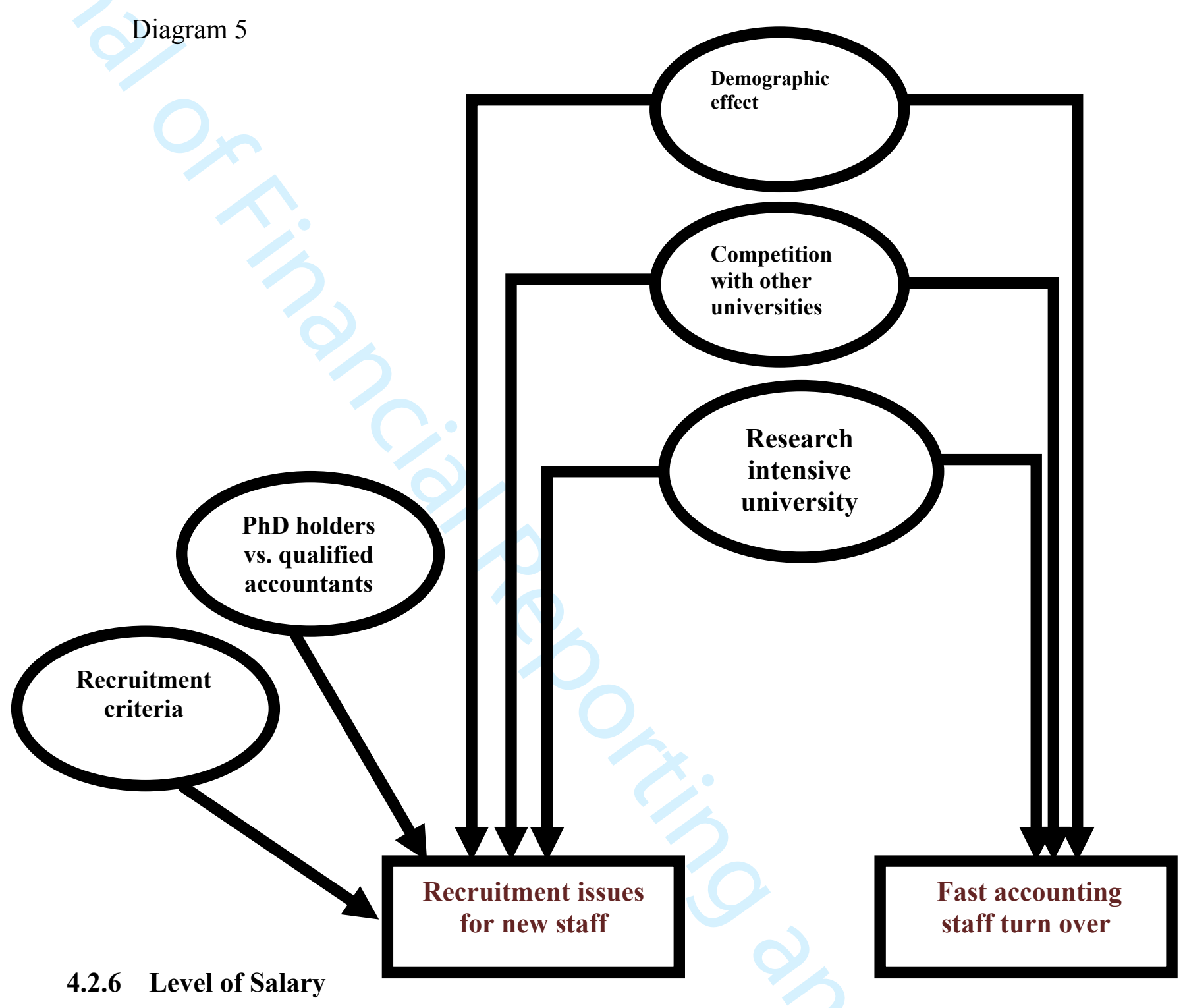

Level of salary plays a role in recruitment of new staff. The cost of living and cost of accommodation in the surrounding area also are high relative to other areas in the UK. This makes it difficult to attract good candidates from other areas in the UK, and makes it difficult for the new career developer to continue with this level of salary. Interviewee 2 said

Well the main challenges are appropriate salary levels. If we paid more it would open up a few doors. We are in London and we should pay a higher degree of London weighting. But the salary scales are not good in universities. When I came into the system we were on the same level as 
general practitioners, doctors, and yet their pay has gone up to a six figure salary and ours has stood still.

The cost of living in London is high, and new junior researchers often prefer to move to places with a much lower cost of living. This is in line of interviewee 3 view, who said "well I think one of the issues here, being in London, is if you are a young lecturer, who is supporting a young family, your salary is not very much here and it doesn't go very far. As you know, you live in the area, accommodation, whether you rent it or you buy it, is really, really expensive and on our salaries it is very difficult to live. So if you are staying at home and looking after children or whatever and only one of you was working, I don't know how somebody with two young children for example, I don't know how somebody like that would live. If I was 25 to 30 or something, staying at home to look after my two children and my husband was a university lecturer, I'd be saying 'We can't do this in London, let's apply for a job in Salford or somewhere up north where I will earn the same salary but I can buy a house that is a tenth of the price of the house that I am going to be living in here', accommodation is a huge part of what we spend our salary on. She continued to say "Also the level of salary is highlighted by interviewee 3 , she said "we find it difficult to recruit accounting and finance staff and also health staff as well because there is kind of a relationship about those, because the argument is why would an accountant, especially in London, who is earning a lot of money, why would they want to come into higher education to earn a tenth, I don't know what the salaries are, I have no idea and I am guessing, but a very, very small salary, compared to what they would earn in practice” From the view of Interviewee 3, one can see that new junior researchers with families may not find it attractive and money wise to live in London due to the high cost of living the Londoners can face. 


\section{Diagram 6}

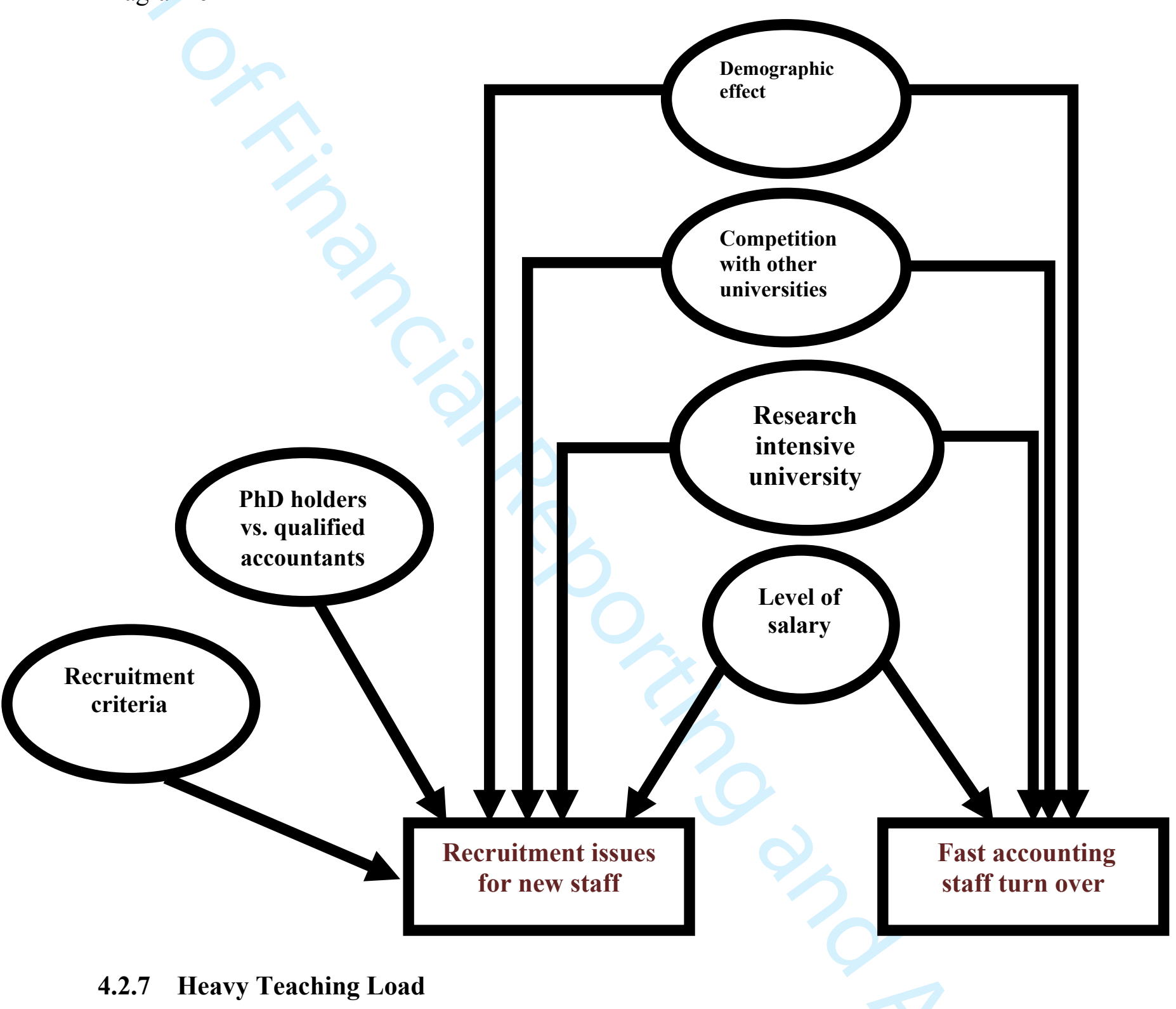

Due to the small number of accounting staff, the teaching load is high compared with other disciplines. This is one of the main challenges the business school under study faces in respect of staff turnover. Interviewee 2 said

Well the accounting challenges are the fact that it is an under resourced subject and we have to teach people from the economics department, social sciences, because they can't recruit sufficient accountants. So we are having a higher load and the student-tutor ratio is poor. That is the big issue for me. 
And staff are fairly stretched here at the moment and that has an impact on their research and what they are writing. 


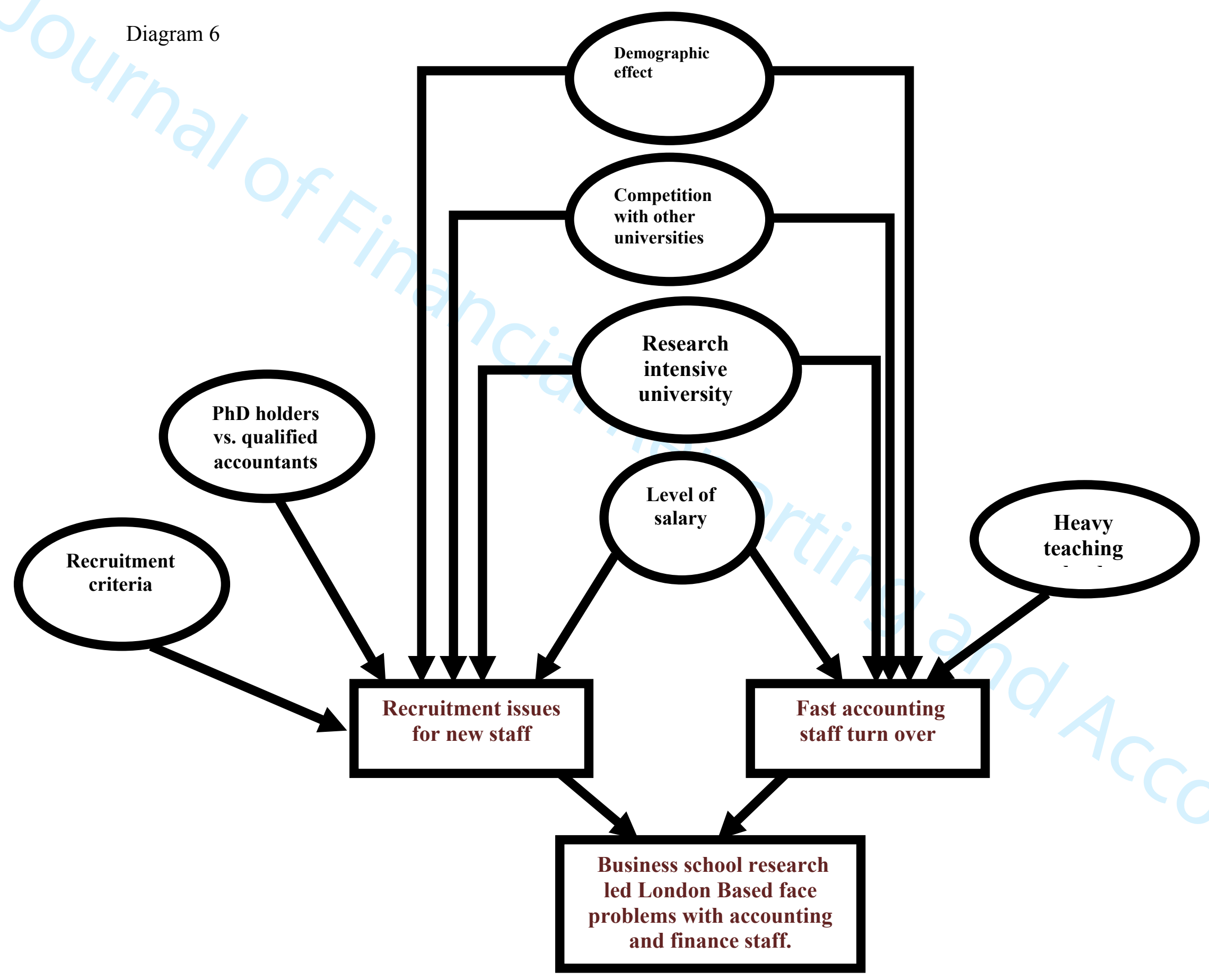




\subsubsection{Response to Internal Promotion}

The issue of promotion is a challenge that can be faced in all types of disciplines, this is what Interviewee 1 mentioned "However it is a widely held belief that it is easier to obtain promotion by applying for a job outside than it is to obtain internal promotion, and this is an HR issue really". So it is not only in the field of accounting. But for any practice discipline, promotion to existing staff plays a vital role when there is a fast turnover. The accounting group is developing a good accounting research record track, within a collegial environment. This may lead to a strong research culture; but the fast accounting staff turnover makes it difficult to achieve the goal of developing a strong research culture. Interviewee 1 commented:

In our group [......], we're trying to build up a strong research culture and it's very difficult to achieve when there is a fast turnover of the research active staff. . .. So it can feel like we were halfway up the hill to building a research culture and the loss of two key members means we have to start again from somewhere near the bottom of the hill. It's easy to climb if you have the whole team to do it with. We're accepting the fact that we've got some members of staff whose contract reflects the fact that they're not research active.

To build and develop strong research cultural accounting group, the promotion is considered to be a challenge. 


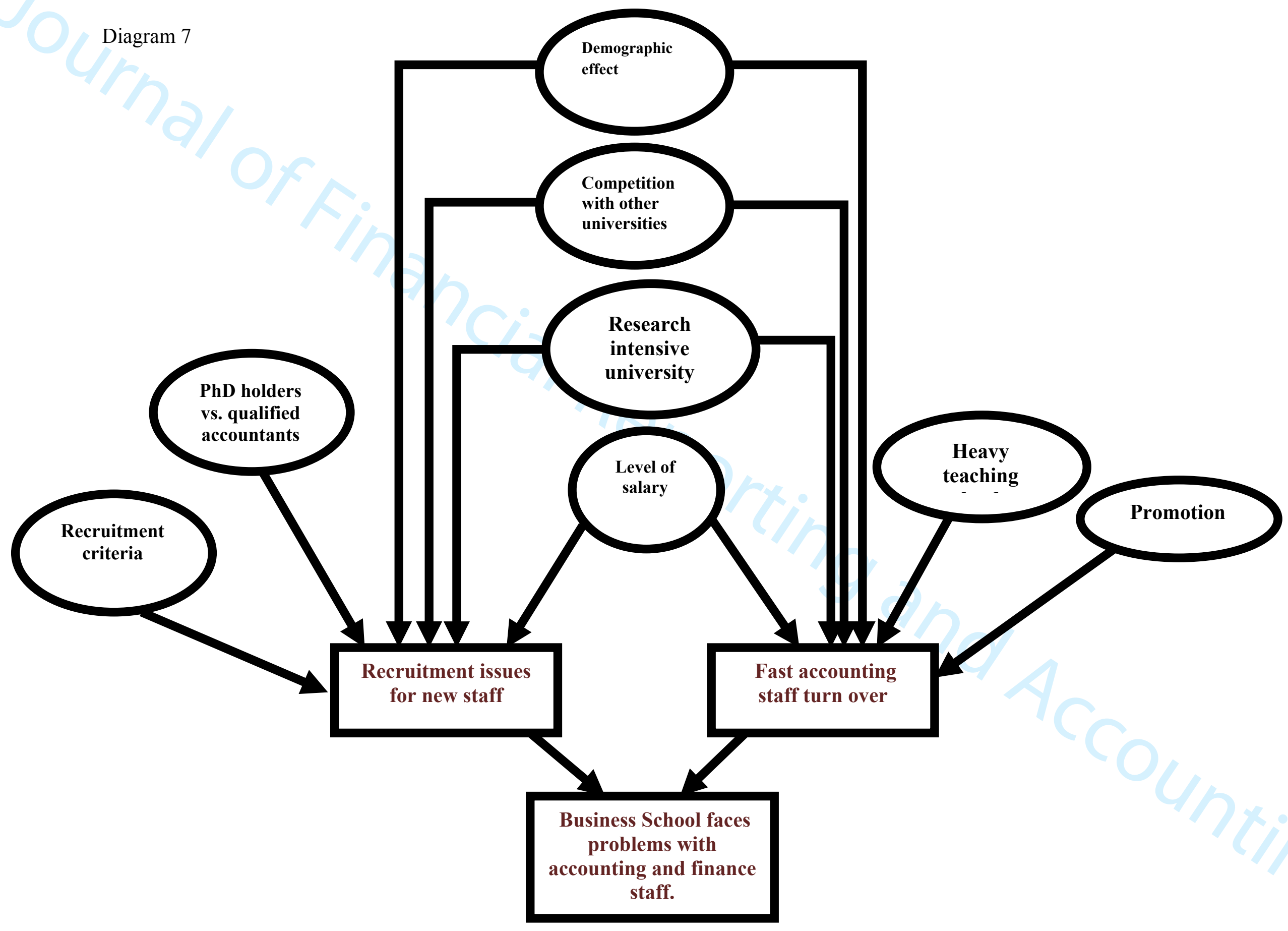




\section{$5 \quad$ Research Novelty, Conclusion, Recommendations and limitations}

The increasing demand for A\&F staff in the UK has led to considerable debate within accounting communities. To contribute to this debate, we aim to generate a theory for the challenges that face a business school in a research led London based University in recruiting suitable accounting academics and the fast turnover of those accounting group members of staff. This issue has a direct effect on the teaching and learning strategy in most business schools. The novelty of this research is based on the induction of the challenges that business school faces, as a case study for a research intensive teaching-led UK university, in recruiting new A\&F appointees and retaining existing members of staff.

With the use of the grounded theory as a research method, data spanning five years was collected from the Human Resources department; there were 21 advertisements for A\&F post over this five-year period. Interviewees were asked about the challenges that business Schools face to deal with the A\&F research group; eight main challenges emerged and a final theory has been generated;

- Recruitment criteria

- $\mathrm{PhD}$ holders vs. qualified professional accountants

- Demographic effect

- Competition with other universities

- Salary level

- Research intensive

- Heavy teaching load

- Response to promotion.

This research explores the challenges that business schools face to find suitable A\&F candidates in a research-led teaching environment, and explores the factors affecting the future of the A\&F academy in business schools. Finding suitable A\&F academia has been a challenge in many countries. As per our discussion in the literature review, it shows that in Australia, accounting education is at a crossroads whilst in America, accounting education is at a tipping point. In the UK, the same issue applies for accounting academia in higher education. 
We look forward to future insights that can solve those issues in the recruitment of new A\&F staff, while retaining the existing A\&F group by seeking different strategies for this group and 'valuing' them.

Finally, the recommendations of this research are as follows:

1 The research intensiveness plays a role in finding suitable A\&F staff and retaining the existing staff. One of the key issues is the number of publications in the accounting field. Publishing in highly rated journals is difficult due to the relatively small number of journals and the arduous review processes. Therefore, the recruitment criteria may be relaxed to the practice discipline applicants in general and to the A\&F applicants in particular. Their industrial and professional experiences can be considered to compensate for their research profiles when deciding their application forms for accounting posts.

2 Give extra support to the practice discipline members of staff and give extra care to the issue of 'promotion'. The fast staff turnover makes it difficult for any research group to grow strong. Therefore, the stability of accounting staff members will increase the group's research culture and enhance and strongly develop greater loyalty to the work place.

3 Increase the intake of PhD students: There should be an overall trend in the UK higher institutions to increase the intake of the number of the PhDs in A\&F research areas by motivating the post graduate students (Master or MBA students) to continue their studies for $\mathrm{PhDs}$ and offer a number of scholarships in A\&F. The professional accounting and bodies can give scholarships to practitioners to continue their PhDs. Boyle et al. (2011) suggest there may be different types of accounting doctoral programs, with varying emphasis on basic research, applied research and the scholarship of teaching. In this case, there will be a strong push to produce and supply move of $\mathrm{PhD}$ holders into the

4 Grow the number of the accounting staff from teaching fellows professional qualifications and teaching experiences. This will have a dual effect, the first is to enhance and enrich the accounting students' learning skills with professional and industrial background. The second effect will be covering high percentage of the teaching quotas for the accounting group leaving the research active members of staff more time to promote their researches. 
One of the most important limitation of this research study is the number of the case study applied in this study. The data collected from one case study makes the research limited to the context of conducting research in a research intensive universities working in London. The number of interviewees is also another limitation in this research. Although the use of the grounded theory makes this limitation inevitable as once the theory is saturated where the improvement is minimized and the theory is generated as in Diagram 7. Another limitation for this research is the location of technology based tools and techniques in accounting. This limitation can be taken forward as an avenue for future research.

Another limitation is the how accounting and finance staff have been using the ICT technology in their teaching and learning, this research limitation can be an avenue for a new research steam in this area.

This research has been taken on one case study in a research intensive University located in London, the future avenue would be research conducted in different areas and with different dimensions. There should be case studies that will conducted to determine the challenges facing the accounting and finance staff recruitment. Another future research dimension is the use of technology and innovation in the selection process

\section{References}

Barnow, B. S., Trutko, J., \& Piatak, J. S. (2013). Occupational labor Shortages: Concepts, causes, consequences, and cures. Kalamazoo, MI: W.E. Upjohn Institute for Employment Research.

Beattie, V., \& Goodacre, A. (2012). Publication records of accounting and finance faculty promoted to professor: Evidence from the UK accounting and finance academic accounting community. Accounting and Business Research, 42(20), 197-231.

Brown, R. (2002). Research and teaching - repairing the damage. Exchange, 3, 29-31.

Brown, R., Jones, M., and Steele, T. (2007), 'Still flickering at the margins of existence? Publishing patterns and themes in accounting and finance research over the last two decades', British Accounting Review, 39, pp. 125-151. 
CAAA (2008), 'Accounting at a Tipping Point' by Sue Haka in the Canadian Accounting Association Annual Conference in May 2008.

Corbin, J. and Strauss, A. (2008). Basics of Qualitative Research: Techniques and Procedures for Developing Grounded Theory. Sage.

Corbin, J., \& Strauss, A. (1990). Grounded theory research: Procedures, canons, and evaluative criteria. Qualitative Sociology, 13, pp.3-21.

De Jager, P. and Frick, B.L. (2016), "Accounting doctorates produced in South Africa 20082014", Meditari Accountancy Research, Vol. 24 No. 3, pp. 438-457.

Deakin, M. (2006), 'Research Led Teaching: a Review of Two Initiatives in Valuing the Link Between Teaching and Research' Journal for Education in the Built Environment Vol. 1, Issue , pp.73-93

Douglas M. Boyle, Dana R. Hermanson and Michael O. Mensah. (2011), 'Addressing the Accounting and Auditing Faculty Shortage: Practitioners' Perceptions of Academia' Current Issues in Auditing 5:1, A70-A85

Duff, A., and Monk, E.A (2006), 'Attitudes of new appointees to accounting and finance departments in the higher education sector revisited' British Accounting Review, 38, pp. 193220.

Evans, E., Burritt, R. and Guthrie, J. (2010), Accounting Education at a Crossroad, Institute of Chartered Accountants of Australia, Sydney.

Gibbs, G. (2002). Institutional strategies for linking research and teaching. Exchange, 3, 8-12.

Glaser, B. and Strauss, A. (1967). The Discovery of Grounded Theory: Strategies For Qualitative Research, Aldine, New York, NY.

Glaser, B.G. (1992), Basics of Grounded Theory Analysis: Emergence versus Forcing, Sociology Press.

Guthrie, J., Evans, E. and Burritt, R. (2014), “Australian accounting academics: challenges and possibilities”, Meditari Accountancy Research, Vol. 22 No. 1, pp. 20-37. 
Heaney, R., Evans, T., Macauley, P., \& Pearson, M. (2013). The impact of Australian higher education policy changes on the production of PhDs in the field of accounting and finance. Accounting and Finance, 53(3), 691-710.

Holland, K. (1991), 'Recruitment by accounting departments in the higher education sector: an analysis of recent employees' British Accounting Review 23, 49-66.

Irvine, H, L Moerman and K Rudkin (2010), 'A green drought: the challenge of mentoring for Australian accounting academics', Accounting Research Journal, Vol.23(2), pp.146-171.

James, K. (2008), “A critical theory perspective on the pressures, contradictions and dilemmas faced by entry-level accounting academics", Critical Perspectives on Accounting, Vol. 19 No. 8, pp. 1263-1295

Kaplan, R.S. (1989), 'Connecting the research-teaching-practice triangle', Accounting Horizons, Vol. 3 No. 1, p. 129.

King, N. (1985). "The Qualitative Research Interiew." Chapter 2 in C.Cassell and G. Symon (Eds.) Organizational Methods in Organizational Research: A Practical Guide. Thousand Oaks, CA: Sage, 1994

Lincoln, Y.S. and E.G. Guba (1985). Naturalistic Inquiry. Beverly Hills, CA: Sage.

Pandit, N. (1996), "The Creation of Theory: A Recent Application of the Grounded Theory Method". The Qualitative Report, Volume 2, Number 4

Parker, L.D., Guthrie, J. \& Linacre, S. (2011), 'The relationship between academic accounting research and professional practice', Accounting, Auditing and Accountability Journal, Vol. 24 No. 1, pp. $5-14$.

Reetley, A. (2004), “A Literature Review on Grounded Theory”. A Dissertation, degree of MASTER IN PSYCHOLOGY in the DEPARTMENT OF PSYCHOLOGY in the FACULTY OF ARTS at the RAND AFRIKAANS UNIVERSITY.

Samkin, G. and Schneider, A. (2014), “The accounting academic”, Meditari Accountancy Research, Vol. 22 No. 1, pp. 2-19. 
Scott, P. (2002). Let's stop trying to separate the inseparable. Exchange, 3, 27-29.

Smith SJ \& Urquhart V (2018), 'Accounting and Finance in UK Universities: Academic Labour, Shortages and Strategies'. British Accounting Review, 50 (6), pp. 588-601. https://doi.org/10.1016/j.bar.2018.03.002

Strauss A, Corbin J (1990). Basics of Qualitative Research: Grounded Theory Procedures and Techniques, Sage, Newbury Park, CA.

Strauss A, Corbin J (1998). Basics of Qualitative Research Techniques and Procedures for Developing Grounded Theory, Sage, USA

Strauss, A. (1987). Qualitative Analysis for Social Scientists. Cambridge University Press, Cambridge, UK.

UCEA, 2002. Recruitment and retention of staff in UK higher education. www.ucea.ac.uk/rrresearchreportfinal.pdf.

Weetman, P. (1993), 'Recruitment by accounting departments in the higher education sector: a comment on the Scottish experience' The British Accounting Review 25, 287-300.

Wilson, R. (1988), 'The academic staff recruitment problem: comments on a note'. The British Accounting Review 20, 275-278.

Wright, S. \& Chalmers, K. (2010), 'The future for accounting academics in Australia', in E. Evans, R. Burritt and J. Guthrie (eds), Accounting Education at a Crossroad in 2010, Institute of Chartered Accountants of Australia, Sydney. 